\title{
Understanding the Complex of Suicide in Depression: from Research to Clinics
}

\author{
Laura Orsolini ${ }^{1,2,3}$, Roberto Latini ${ }^{2}$, Maurizio Pompili ${ }^{4}$, Gianluca Serafini ${ }^{5}$, Umberto Volpe ${ }^{6}$, \\ Federica Vellante ${ }^{7}$, Michele Fornaro ${ }^{3,8}$, Alessandro Valchera ${ }^{3,9}$, Carmine Tomasetti ${ }^{10}$, \\ Silvia Fraticelli ${ }^{7}$, Marco Alessandrini ${ }^{7}$, Raffaella La Rovere ${ }^{11}$, Sabatino Trotta ${ }^{11}$, \\ Giovanni Martinotti ${ }^{7}$, Massimo Di Giannantonio ${ }^{7}$, and Domenico De Berardis ${ }^{7,12} \bowtie$
}

${ }^{1}$ Psychopharmacology, Drug Misuse and Novel Psychoactive Substances Research Unit, School of Life and Medical Sciences, University of Hertfordshire, Hatfield, UK

${ }^{2}$ Neomesia Mental Health, Villa Jolanda Hospital, Jesi, Italy

${ }^{3}$ Polyedra, Teramo, Italy

${ }^{4}$ Department of Neurosciences, Mental Health and Sensory Organs, Suicide Prevention Center, S. Andrea Hospital, Sapienza University, Rome, Italy ${ }^{5}$ Department of Neuroscience, Rehabilitation, Ophthalmology, Genetics, Maternal and Child Health, Section of Psychiatry, University of Genoa, IRCCS Ospedale Policlinico San Martino, Genoa, Italy

${ }^{6}$ Department of Clinical Neurosciences/DIMSC, School of Medicine, Section of Psychiatry, Polytechnic University of Marche, Ancona, Italy

${ }^{7}$ Department of Neuroscience, Imaging and Clinical Science, Chair of Psychiatry, University of "G. D'Annunzio", Chieti, Italy

${ }^{8}$ Department of Psychiatry, Federico II University, Naples, Italy

${ }^{9}$ Villa S. Giuseppe Hospital, Hermanas Hospitalarias, Ascoli Piceno, Italy

${ }^{10}$ Department of Mental Health, National Health Service, Psychiatric Service of Diagnosis and Treatment,

Hospital "SS. Annunziata" ASL 4, Giulianova, Italy

${ }^{11}$ Department of Mental Health, National Health Service, Azienda Sanitaria Locale, Pescara, Italy

${ }^{12}$ Department of Mental Health, National Health Service, Psychiatric Service of Diagnosis and Treatment, Hospital "G. Mazzini", ASL 4, Teramo, Italy

Objective Amongst psychiatric disorders, major depressive disorder (MDD) is the most prevalent, by affecting approximately 15-17\% of the population and showing a high suicide risk rate equivalent to around $15 \%$. The present comprehensive overview aims at evaluating main research studies in the field of MDD at suicide risk, by proposing as well as a schematic suicide risk stratification and useful flow-chart for planning suicide preventive and therapeutic interventions for clinicians.

Methods A broad and comprehensive overview has been here conducted by using PubMed/Medline, combining the search strategy of free text terms and exploded MESH headings for the topics of 'Major Depressive Disorder' and 'Suicide' as following: ((suicide [Title/Abstract]) AND (major depressive disorder [Title/Abstract])). All articles published in English through May 31, 2019 were summarized in a comprehensive way.

Results Despite possible pathophysiological factors which may explain the complexity of suicide in MDD, scientific evidence supposed the synergic role of genetics, exogenous and endogenous stressors (i.e., interpersonal, professional, financial, as well as psychiatric disorders), epigenetic, the hypothalamic-pituitary-adrenal stress-response system, the involvement of the monoaminergic neurotransmitter systems, particularly the serotonergic ones, the lipid profile, neuro-immunological biomarkers, the Brain-derived neurotrophic factor and other neuromodulators.

Conclusion The present overview reported that suicide is a highly complex and multifaceted phenomenon in which a large plethora of mechanisms could be variable implicated, particularly amongst MDD subjects. Beyond these consideration, modern psychiatry needs a better interpretation of suicide risk with a more careful assessment of suicide risk stratification and planning of clinical and treatment interventions.

Psychiatry Investig 2020;17(3):207-221

Key Words Major depressive disorder, Suicide, Depression, Suicidal risk.

Received: October 16, 2019 Revised: February 23, 2020 Accepted: February 27, 2020

$\triangle$ Correspondence: Domenico De Berardis, MD, PhD

Department of Mental Health, National Health Service, Psychiatric Service of Diagnosis and Treatment, “G. Mazzini” Hospital, p.zza Italia 1, 64100 Teramo, Italy Tel: +39-0861429708, Fax: +39-0861429709, E-mail: domenico.deberardis@aslteramo.it

(c) This is an Open Access article distributed under the terms of the Creative Commons Attribution Non-Commercial License (https://creativecommons.org/licenses/by-nc/4.0) which permits unrestricted non-commercial use, distribution, and reproduction in any medium, provided the original work is properly cited 


\section{INTRODUCTION}

Suicide is a leading public health problem, being a leading cause of injury and death at a worldwide level, with approximately one million people who die by suicide per year and an estimate of around one suicide death occurring every 40 seconds. ${ }^{1-3}$ Suicide is ranked as the 2 th leading cause of death among people aged 10 to 34 and the tenth among all age groups. ${ }^{3,4}$ Notably, suicidal behaviour has been implicated as a co-morbidity of several neuropsychiatric disorders, including borderline personality disorder, schizophrenia, bipolar disorder and major depressive disorder (MDD), being considered one of the leading causes of preventable death amongst people affected with mental disorders. ${ }^{5} \mathrm{MDD}$ is a common psychiatric disorder which is associated with significant personal suffering, physical and mental disability, with a global point prevalence being around $4.7 \%$ and a lifetime prevalence ranging from $3 \%$ in Japan to $16.9 \%$ in USA, whilst in other Western countries the figures varied between $8 \%$ and $17 \% .^{6-8}$ The association between MDD and suicide attempts (SA) and/or ideation (SI) has been well documented, being SI and suicidal behaviour frequently reported during depressive episodes, with a suicide risk rate equivalent to around $15 \% .{ }^{3,9-11}$ Furthermore, epidemiological studies reported as well that MDD subjects with comorbid anxiety disorders were among the main predictors of SA amongst depressed suicide subjects. ${ }^{12}$ However, the role of comorbid anxiety disorders, in increasing suicidal risk is still a matter of debate although it has been well recognized that the association between MDD and anxiety disorders appear to have more a synergic role in increasing suicidal risk. ${ }^{13}$ Despite possible pathophysiological factors which may determine/ explain the correlation between depression and suicidal risk are not yet fully understood, it has been supposed the synergic role of genetics, exogenous and endogenous stressors (i.e., interpersonal, professional, financial, as well as psychiatric disorders), the hypothalamic-pituitary-adrenal (HPA)-stressresponse system, epigenetics, the involvement of the monoaminergic neurotransmitter systems, particularly the serotonergic ones, the role of specific neurotrophins, such as the Brain-derived neurotrophic factor (BDNF), etc. ${ }^{14-16}$ Overall, suicide is a complex phenomenon and, according to the World Health Organization, ${ }^{3}$ suicidal behaviour may be defined as "a range of behaviours that include thinking about suicide (suicidal ideation, SI), suicide threat (ST), planning for suicide (SP), attempting suicide (SA) and suicide itself (CS)" (Table 1). The complex phenomenon is not due to a simple etiology but rather is the result of a complex interaction of genetic vulnerability, stress factors, underlying psychopathology and social aspects, even though the precise pathophysiological mechanisms underlining the suicide behaviour is not yet fully understood and probably not completely investigated. Being literature published so far on suicide risk within patients affected with MDD extremely varied and broad, the present paper aimed at overviewing only a selected range of suicide risk predictors in MDD subjects, by analysing both research and clinical evidence, as primary objective, to try identifying a pathophysiological as well as clinical perspective, able to answer to questions regarding performing preventive tools (if any), easy to measure and useful for clinical practice. Furthermore, as secondary objective, a schematic suicide risk stratification proposal together with a useful flow-chart for planning suicide preventive and therapeutic interventions has been here proposed for clinicians working in the field of Mental Health, particularly with those subjects affected with mood disorders at higher suicidal risk.

\section{MATERIAL AND METHODS}

\section{Search sources and strategies}

A broad overview has been here conducted with literature searches performed by using PubMed/Medline. We combined the search strategy of free text terms and exploded MESH headings for the topics of 'Major Depressive Disorder' and 'Suicide' as following: ((suicide [Title/Abstract]) AND (major depressive disorder [Title/Abstract])). All articles published in English have been properly selected and screened. Studies published through May 31, 2019 were here considered. In addition, secondary searches were performed using the reference listing of all eligible as well as relevant articles and consultation with experts in the field and or manual search.

\section{Study selection, data extraction and management}

We considered studies evaluating the Suicide in MDD, by excluding other mental disorders in comorbidity, including anxiety disorders and/or bipolar disorder and/or psychotic disorders. We examined all titles and abstracts, and obtained full texts of potentially relevant papers. After this first screening, we followed a two-step process: 1) in a first phase, we specifically selected all papers containing relevant data on suicide risk factors in MDD subjects (with the aim to identify which suicide risk factors better investigate in the next step, with the aim to address those aspects useful for preventive strategies); 2) in the second phase, we specifically selected a range of macro-categories to be better deepened, as follows: 1) The role of genetic vulnerability and epigenetic modulation in determining suicide risk in MDD subjects; 2) the role of HPA axis in suicide risk in MDD subjects; 3 ) the role of serotoninergic system in suicide risk in MDD subjects; 4) the role of neurotrophins and neuroplasticity in suicide risk in 
Table 1. Definitions and suicide risk formulation

\begin{tabular}{|c|c|c|}
\hline $\begin{array}{l}\text { Suicidal } \\
\text { ideation (SI) }\end{array}$ & $\begin{array}{l}\text { Thoughts, fantasies } \\
\text { and wishes about ending } \\
\text { one's own life }\end{array}$ & $\begin{array}{l}\text { If a patient states that SI is present, the clinician is obligated to explore SI furtherly by posing } \\
\text { the following questions: } \\
\text { - Content (active thoughts of suicide vs. passive wishes for death) } \\
\text { - Content (planning or not?) } \\
\text { - Duration of SI } \\
\text { - Frequency of SI } \\
\text { - Intensity of SI } \\
\text { - Controllability or not? } \\
\text { - Expectations about death (i.e., thoughts of reuniting with lost significant others; thoughts } \\
\text { of evoking punishment of others; the need to escape a painful physical or psychological } \\
\text { situation; thoughts of harming others first before harming him or herself) }\end{array}$ \\
\hline $\begin{array}{l}\text { Suicide } \\
\text { threat (ST) }\end{array}$ & $\begin{array}{l}\text { Thoughts of engaging in } \\
\text { self-injurious behavior that } \\
\text { are verbalized and intended } \\
\text { to lead others to think that } \\
\text { one wants to die, despite no } \\
\text { intention of dying (e.g., 'if you } \\
\text { leave me, I will kill myself') }\end{array}$ & $\begin{array}{l}\text { If patient manifests a ST, clinicians should furtherly investigate the followings: } \\
\text { - Are there non-suicidal self-injurious thoughts? e.g., are there any thoughts of engaging } \\
\text { in self-injurious behavior characterized by the deliberate destruction of body tissue in the } \\
\text { absence of any intent to die or not? }\end{array}$ \\
\hline $\begin{array}{l}\text { Suicide } \\
\text { plan (SP) }\end{array}$ & $\begin{array}{l}\text { Having plans on how to } \\
\text { end one's own life }\end{array}$ & $\begin{array}{l}\text { If a patient has a SI, clinicians should carefully investigate the presence and characteristics } \\
\text { of SP as following: } \\
\text { - Has a specific plan been formulated or implemented, including a specific method, } \\
\text { place and time? } \\
\text { - What is the anticipated outcome of the plan? } \\
\text { - Are the means of committing suicide available or readily accessible? } \\
\text { - Does the patient know how to use these means? } \\
\text { - What is the lethality of the plan? (patient's conception of lethality vs objective lethality?) } \\
\text { - What is the likehood of rescue? } \\
\text { - Have any preparations been performed (e.g., changing wills, suicide notes, etc.) or } \\
\text { how close has the patient come to completing the plan? } \\
\text { - Has the patient practiced the suicidal act or has an actual attempt already been made? } \\
\text { - Is there a history of impulsive behaviours or SUD that might increase impulsivity? } \\
\text { - What is the patient's ability to control impulsivity? }\end{array}$ \\
\hline $\begin{array}{l}\text { Suicide } \\
\text { attempt } \\
\text { (SA) }\end{array}$ & $\begin{array}{l}\text { Self-destructive act with } \\
\text { intent to end one's own life, } \\
\text { even though is not fatal }\end{array}$ & $\begin{array}{l}\text { If patient did a SA, clinicians should furtherly investigate the followings: } \\
\text { - Is a self-injurious behaviour accompanied by any intent to die or not? If yes, it is a real SA } \\
\text { - Is a non-suicidal self-injurious behaviour? i.e., a deliberate destruction of body tissue in } \\
\text { the absence of any intent to die? } \\
\text { - Investigate if patient had a previous SA and/or a family history of a SA or CS } \\
\text { - Managing patient as follows: } \\
\text { Medical stabilization } \\
\text { Inpatient hospitalization }\end{array}$ \\
\hline $\begin{array}{l}\text { Completed } \\
\text { suicide } \\
\text { (CS) }\end{array}$ & $\begin{array}{l}\text { Self-injurious behaviour } \\
\text { with intent to end one's } \\
\text { own life and is fatal }\end{array}$ & $\begin{array}{l}\text { Clinicians should apply post-suicide interventions, i.e., helping family, friends and coworkers } \\
\text { understand why suicide victims killed themselves and decreasing the assumption of } \\
\text { inappropriate guilt for the death } \\
\text { - Identify 'survivors' at risk of suicide } \\
\text { - Prevent PTSD, complicated grief, depressive symptoms }\end{array}$ \\
\hline
\end{tabular}

SUD: substance use disorder, PTSD: posttraumatic stress disorder

MDD subjects; 5) the role of neuro-immunological mediators/biomarkers in suicide risk in MDD subjects; 6) the role of metabolic factors (i.e., lipid profile) in suicide risk in MDD subjects; 7) the role of cognitive domains and neuropsychological dimensions in suicide risk in MDD subjects; 8) the role of personality traits in suicide risk in MDD subjects; 9) evidences coming from neuroimaging studies in suicide risk in MDD subjects. Working independently and in duplicate, two reviewers (LO and DDB) read the papers and determined whether they met inclusion criteria. LO and DDB, in- 
dependently extracted the data on the above subcategories and selected relevant data useful for the present overview. Disagreements were resolved by discussion and consensus with a third member of the team (FV). All English-language articles identified by the data sources, reporting data on suicide in MDD, both from a preclinical and clinical perspective, have been considered for the present overview. Data collected were then summarized according to the abovementioned categories.

\section{RESULTS}

\section{Risk factors}

Although the aetiology of suicide and MDD is certainly complex, some suicide risks factors are thought to contribute to the risk of suicidal behaviour, including biological/individual, psychological social, clinical/symptomatological and

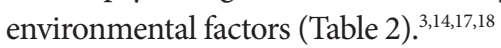

\section{Genetic vulnerability and epigenetic modulation}

Family studies suggest that $\mathrm{SA}$ and fulfilled suicide show familial accumulation, ${ }^{19}$ with heritability estimates of suicidal behavior between $30 \%$ and $55 \%$ and an increased risk of at least two-fold. ${ }^{20-23}$ Inherited genetic differences have a relevant role in suicidality, as demonstrated by twin studies, particularly that monozygotic twins' concordance for the CS is notably higher than in dizygotic twin pairs, being respectively $24.1 \%$ and $2.8 \%{ }^{23-25} \mathrm{~A}$ genome-wide association study (GWAS) of suicidal thoughts and behaviour in MDD, indicated a polygenetic architecture with multiple genes implicated even though with small effects. ${ }^{26}$ However, although several GWAS studies have been conducted on SA examining individuals with MDD, comparing suicide attempters with non-attempters and testing for genetic variants that might contribute independently to $S A,{ }^{27-31}$ epidemiological evidence suggests that the inheritance of suicidality is likely to be independent of the underlying MDD, by supporting a distinct genetic contribution to suicidality. ${ }^{32}$ Polygenic risk scores for SA have shown modest predictive capability in independent samples, and small but significant single-nucleotide polymorphism (SNP) heritability estimates for SA have been reported. ${ }^{28,33,34}$ A significant association between two SNPs (rs12415800 and rs4746720 in 3'UTR) and CS amongst MDD women aged more than 50 years compared to healthy controls. ${ }^{35}$ The FKBP5 gene which encodes the FK506 binding protein 51 (FKBP51) and participates as regulator of the glucocorticoid receptor (GR) activity, has received an increasing attention as well, in relation to the suicidal behaviour. ${ }^{36,37}$ FKBP51 is an important modulator of stress response. ${ }^{38}$ FKBP5 SNPs have been associated with an increased risk of MDD and SA. ${ }^{39-43}$ Amongst the serotonin system candidate genes for $\mathrm{SB}$, many genetic association studies have focused on the SLC6A4 (Solute Carrier Family 6, Member 4) gene, ${ }^{44,45}$ located on chromosome 17 (17q11.2) which encodes for the serotonin transporter, a transmembrane presynaptic protein involved in the reuptake of the released serotonin from the synaptic cleft. ${ }^{46}$ Moreover, the transcriptional activity of SLC6A4 gene is modulated by a 44 base-pair insertion/deletion polymorphism, commonly known as 5-HTTLPR (serotonin transporter linked polymorphic region polymorphism-rs4795541), located upstream of the transcription start site. Genetic studies demonstrated that depressed suicide victims had a smaller amount of serotonin transporters in the PFC, hypothalamus and brainstem compared to not suicide MDD subjects. ${ }^{47}$ Moreover, a recent GWAS study identified GWS SNPs in proximity to genes involved in the regulation of circadian clock rhythms (ARNTL2), anaerobic energy production (LDHB) and catecholamine catabolism (FAH), amongst MDD patients with SA. ${ }^{48}$ Therefore, further studies should better evaluate which is common (if any) genetic load in MDD subjects at risk for SA and/or SC and the correlation (if any) is dependent or independent.

Furthermore, distal (predisposing) factors interact with proximal (precipitating) factors in determining suicidal event, i.e., genetic predisposition/vulnerability, early adversities and associated epigenetic modifications, and together may modulate suicidal behaviour and personality traits associated to suicide in MDD. ${ }^{49}$ Early life adversity is considered one of the strongest risk factor for SA, i.e., exposure to maltreatment during the early phases of a person's development increases the risk of SB thought the lifespan within 2- to 5 -fold times. ${ }^{50}$ In fact, these events may epigenetically regulate key emotional and behavioural systems which in turns may contribute to the development of MDD and suicide behaviour, mainly by inducing a DNA methylation. ${ }^{51-54} \mathrm{~A}$ study investigated whether epigenetic modifications of stress-related genes play a role in suicidal behaviour and whether these modifications are common to or independent of MDD, by reporting a significant increase I DNA methylation of stressrelated genes including BDNF, NR3C1, FKBP5, and CRHBP amongst MDD subjects (with and without SI) compared to healthy controls, together with a concomitant decrease in expression of $\mathrm{BDNF}, \mathrm{NR} 3 \mathrm{C} 1$, and FKBP5 transcript variant 1, 2 and 3 (but not 4) amongst MDD-suicide subjects compared to healthy controls. ${ }^{54}$

\section{The hypothalamic-pituitary-adrenal axis}

The HPA axis is the major neuroendocrine system involved in the regulation of the body's response to stress. ${ }^{14}$ The stressrelated theory of MDD states that chronic stress may lead to long-term activation of the HPA axis, which may result in re- 
Table 2. Suicide risk and protective factors in MDD

\begin{tabular}{|c|c|}
\hline Risk factors & Protective factors \\
\hline \multicolumn{2}{|l|}{ Factors affecting threshold for suicidal behaviour } \\
\hline Demographic and individual risk factors & Demographic and individual risk factors \\
\hline - Male gender & - No personal history of attempted suicide \\
\hline - Younger and/or older age & - No family history of suicide and/or attempted suicide \\
\hline - Personal history of attempted suicide & - No personal and/or family history for psychotic symptoms and/ \\
\hline - Positive family history of suicide & or disorders \\
\hline - Marital isolation & - No personal and/or family history for SUD and/or AUD \\
\hline - Chronic physical illness & - Religious or moral constraints \\
\hline - Parental loss through death before age 11 & - Concern about social disapproval \\
\hline - Child history of physical or sexual abuse & - Better coping skills \\
\hline - Corporal punishment in adolescence & - Feelings of responsibility towards family \\
\hline Symptom risk profile risks & • Living with children under age 18 \\
\hline - Presence of hopelessness & - Supportive relationships \\
\hline - Presence of low self-esteem & - Positive and valid therapeutic alliance \\
\hline - Feelings of whortlessness & - Better impulsivity control \\
\hline - Feelings of helplessness & - Better emotional regulation \\
\hline \multicolumn{2}{|l|}{ - Feelings of entrapment } \\
\hline \multicolumn{2}{|l|}{ - Anhedonia } \\
\hline \multicolumn{2}{|l|}{ - Cognitive rigidity } \\
\hline \multicolumn{2}{|l|}{ - Impaired problem solving and/or decision making } \\
\hline \multicolumn{2}{|l|}{ - Impulsive aggressive personality trait } \\
\hline \multicolumn{2}{|l|}{ - Early onset of MDD } \\
\hline \multicolumn{2}{|l|}{ - First episode of MDD } \\
\hline \multicolumn{2}{|l|}{ - Comorbid SUD and/or AUD } \\
\hline \multicolumn{2}{|l|}{ - Comorbid BPD } \\
\hline \multicolumn{2}{|l|}{ Suicide risk factors as triggers } \\
\hline Demographic and individual risk factors & Symptom protective risks \\
\hline - Social, financial or family crisis or loss & - Good self-esteem \\
\hline - Contagion or recent exposure to suicide & - Self-efficacy \\
\hline - Social support lacking & - Good problem-solving skills \\
\hline Symptom risk profile risks & - Willingness to seek help \\
\hline - Comorbid anxiety symptoms & - Positive coping skills \\
\hline - Comorbid panic disorder & • Emotional stability \\
\hline - Acute alcohol and/or substance intoxication & - Responsibility to family \\
\hline - Presence of psychotic symptoms & • Developed self-identity \\
\hline - Severity of depressive episode of MDD & - Healthy lifestyle choices \\
\hline \multicolumn{2}{|l|}{ - Post-partum } \\
\hline Circumstantial risk profile risks* & Circumstantial risk profile risks* \\
\hline - Reduced or absent desire to live & - Absence of SI, SP, SB or SHB \\
\hline - Active SI & - No feelings of hopelessness, desire to die \\
\hline - Presence of a SP & - Good connectedness \\
\hline - Presence of SB or SHB & - Good therapeutic adherence \\
\hline - Acute alcohol and/or substance intoxication & - Positive therapeutic relationship and alliance \\
\hline - Unresolvable problems & - Good future planning \\
\hline \multirow{4}{*}{$\begin{array}{l}\text { - Presence of auditory imperative hallucinations } \\
\text { (order to suicide oneself) }\end{array}$} & - Solving of previous critical problems \\
\hline & • Positive social support \\
\hline & - Moral objections towards SB \\
\hline & - Fear of social disapproval towards SB \\
\hline
\end{tabular}

*these factors should be evaluated, in the moment of clinical observation (Interview Risk Profile), by a psychiatrist or a medical doctor. MDD: major depressive disorder, SUD: substance use disorder, AUD: alcohol use disorder, BPD: borderline personality disorder, SI: suicidal ideation, SP: suicide planning, SB: suicidal behaviour, SHB: self-harm behaviour 
ductions in the volume or impaired function of the hippocampus. ${ }^{55}$ The corticotrophin-releasing hormone (CRH) and vasopressin are hormones released from neurosecretory nerve terminals and act synergistically to stimulate the secretion of stored adrenocorticotrophic hormone (ACTH) from corticotrophin cells, which in turns stimulates biosynthesis of corticosteroids..$^{14}$ Prospective biological studies suggest that dysfunctions in the HPA axis have some predictive power for suicide in MDD. ${ }^{14}$ Subjects affected with MDD who manifest a suicidal behaviour show an increased level of CRH in the cerebrospinal fluid compared to not suicide MDD subjects. ${ }^{56}$ Several studies reported that cortisol non-suppression in response to the dexamethasone challenge test represents a strong predictor of suicidal behaviour in MDD. ${ }^{14,57-60}$

\section{Serotonergic system}

The serotonin system has been widely investigated in studies of both MDD subjects and suicidal behaviour. Postmortem studies of the suicidal brains have shown evidence of serotonin dysfunction amongst MDD subjects. ${ }^{61-63}$ Serotonin transporters have been reported to be reduced in the prefrontal cortices, hypothalamic, occipital cortices, and brainstems of subjects affected with MDD who have committed suicide. ${ }^{45}$ Studies demonstrated a lower concentration of the serotonin metabolite 5-hydryndolacetic acid (5-HIAA) in the cerebrospinal fluid of depressed patients prone to develop suicidal behaviour ${ }^{64}$ as well as lower levels of serotonin (5HT) and 5-HIAA in the brainstem of suicide victims, ${ }^{65-67}$ compared to non-suicide MDD subjects. The serotonin transporter (5-HTT) is the major determinant of 5-HT inactivation following 5-HT release at synapses, a decrease in 5-HTT has been observed in suicide victims with MDD. ${ }^{68}$ Some postmortem studies have reported increased $5-\mathrm{HT}_{2 \mathrm{~A}}$ receptor binding in the prefrontal cortex of suicidal individuals with MDD. ${ }^{69,70}$ A meta-analysis of prospective biological studies estimated the odds ratio for the prediction of suicide completion to be 4.5-fold greater for MDD subjects with low levels of 5-HIAA in the cerebrospinal fluid compared to subjects with high levels of 5-HIAA. ${ }^{71}$ The serotonin transporter gene is located on chromosome 17q11.1-q12 and two polymorphisms have been reported. ${ }^{72}$ Electroencephalographic (EEG) changes and various polysomnographic findings can reflect the central serotonin activity and demonstrate that high suicidality score has been associated with shorter REM (rapid eye movement) latency. ${ }^{73}$ An increase of REM time and activity in MDD subjects with SA has been associated with reduced serotonin activity or 5-HIAA levels in cerebrospinal fluid. ${ }^{74}$

\section{Neuroplasticity, brain-derived neurotrophic factor and nerve growth factor}

Several theories have been proposed to explain the biological substrates of suicide behaviour, including the role of specific neurotrophins, such as the brain-derived neurotrophic factor (BDNF) and the nerve growth factor (NGF). ${ }^{75-80}$ The "neurotrophic hypothesis" of MDD seeks to understand depression through regulatory proteins (e.g., BDNF) which promote neuroplasticity, adult neurogenesis and neurotransmission. ${ }^{81-83}$ Changes in brain structures and function, such as reduced neuronal cell numbers, density and size, as well as decreased cortical thickness and changes in synaptic circuits, may be associated with MDD, stress and suicidal behaviour. ${ }^{84,85}$ In fact, both MDD and suicidal behaviour involve altered neural plasticity, resulting in an abnormal central nervous system response to stressors and environmental outcomes. ${ }^{79}$ The neurotrophic factors activate the neuroendocrine cells and the neuronal responses, by regulating the growth and proliferation of glial cells, modulating the activity of endogenous opioid peptides, activating the HPA axis, exerting effects on corticotrophin releasing hormone-producing neurons, and acting on the endothelial cells of the cerebral vasculature or on the glial cells in the circumventricular organs. ${ }^{86}$ Furthermore, the neurotrophic factors may influence as well as the metabolism of the noradrenergic, serotonergic and dopaminergic systems. ${ }^{87}$ It has been as well supposed that low BDNF levels relate to suicidality rather than to MDD specifically, ${ }^{88}$ even though low BDNF levels have been reported in MDD subjects who attempted suicide when compared to non-suicidal MDD and healthy controls. ${ }^{77,80,89}$ A recent study found that serum BDNF levels were significantly lower in MDD with SI compared to MDD without SI but were not significantly correlated with MDD severity. ${ }^{90}$ CREB1 (cyclic adenosine monophosphate response element binding protein) is a transcription factor that controls the transcription of numerous neuronally expressed genes such as BDNF. ${ }^{91-95}$ There is evidence for CREB1 playing an important role in the neurobiology of suicidal behaviour. ${ }^{96-99}$ Nerve growth factor (NGF) is a neurotrophin, produced in the cortex, hippocampus and hypothalamus as well as in the peripheral nervous system and immune system. ${ }^{100}$ Neurotrophins generally are implicated in neuronal survival, differentiation, connectivity and plasticity during development and adulthood. ${ }^{101}$ Clinical studies have detected reduced levels of NGF in patients with MDD and suicide victims, particularly in the prefrontal cortex and the hippocampus, ${ }^{101-104}$ areas implicated in the cognition and mood regulation as well as in the pathophysiology of affective disorders and suicide. ${ }^{102}$ Furthermore, the hippocampus is an area affected by early stress, which in turns is implicated in the suicidal behaviour. ${ }^{101}$ However, 
studies specifically investigating NGF, MDD and suicide risk are scarce and extremely heterogeneous from a methodological point of view, hence, further studies should be carried out in order to better clarify the potential role of NGF in increasing suicide risk amongst MDD subjects.

\section{Neuro-immunological markers}

Inflammatory mediators and oxidative stress leading to excitotoxicity may play a critical role in the pathophysiology of MDD and suicide, including an imbalance between proinflammatory cytokines (i.e., interleukin IL-1b, IL-2, IL-6, interferon-gamma INF- $\gamma$ ) and tumor necrosis factor-alpha (TNF- $\alpha$ ) versus anti-inflammatory cytokines (i.e., IL-4 and IL-10); or increased levels of pro-inflammatory cytokines and level of severity of MDD. ${ }^{105}$ Therefore, a dysregulation of immune response could be a contributing factor to MDD at risk of suicide, including the vascular endothelial growth factor (VEGF) and kynurenine levels. ${ }^{105,106}$ Moreover, several findings suggest that suicidal MDD patients display a distinct peripheral blood cytokine profile compared to non-suicidal patients with MDD, being specific changes in inflammatory cytokines levels most frequently associated with MDD and suicidality. ${ }^{105}$ In particularly, lower IL-8 levels linked to a reduced neuroprotection and higher IL-13 levels have been found in MDD patients with SI compared to those MDD subjects without; ${ }^{105}$ whilst increased levels of interferon-gamma (INF- $\gamma$ ) and IL-6 appeared to be more robustly associated with SA in MDD, ${ }^{107}$ even though previous studies evaluating suicidal MDD patients reported decreased levels of INF- $\gamma$ and IL-6, compared with non-suicidal MDD patients. ${ }^{108,109}$ Indeed, other studies are quite conflicting in findings, for instance, high IL-4 levels have been found in MDD women with CS, suicidal MDD patients and both suicidal and nonsuicidal MDD subjects. ${ }^{105}$ Suicidal MDD subjects, particularly those who were violent SA, were are likely to own higher IL-6 and lower IL-2 levels compared to non-suicidal MDD subjects and healthy controls. ${ }^{105}$ Furthermore, higher TNF- $\alpha$ levels have been reported as well in suicidal MDD subjects compared to non-suicidal MDD and healthy controls, even though some evidence appear to be contrasting. ${ }^{105}$ A key biological pathway which may link inflammation and MDD is the activation of the HPA axis by cytokines, mainly due to psychosocial stressors, resulting in increased cortisol levels and release of monoamines which may initially enhance inflammatory signaling pathways and active immune system. However, not all studies demonstrated a positive correlation between inflammatory cytokines and suicidal behaviour in MDD subjects, hence, further studies should better investigate this correlation (if any). For a more complete overview, see Marini et al. ${ }^{110}$

\section{Metabolic pattern}

Large randomized clinical trials of cholesterol-lowering drugs and meta-analytic studies reported an increase in violence-related deaths, including suicide, amongst individuals taking serum cholesterol-lowering medications. ${ }^{111,112}$ Suicidal MDD patients tend to have dysregulated lipid levels compared with non-suicidal patients. ${ }^{113-115}$ Clinical studies carried out on psychiatric subjects, including MDD subjects, revealed a relationship between lower total cholesterol levels and suicidal behaviour. ${ }^{116-120}$ Lower levels of total cholesterol in MDD patients with SI, compared to non-suicide MDD subjects, have been reported in a recent meta-analysis. ${ }^{121}$ Low triglycerides, low levels of low-density lipoprotein (LDL) and low levels of high-density lipoprotein (HDL) are significantly related to suicidality in MDD patients. ${ }^{122,123}$ A proposed hypothesis suggested that reduced cholesterol levels may reduce serotonin precursors and modify the functions and viscosity of serotonin receptors and transporters, by increasing one's tendencies towards impulsive, aggressive, and suicidal behaviour. Low serum triglycerides concentrations may also alter serotonin metabolism, leading to poor control of aggressive impulses in MDD subjects, by resulting in an increased suicidality risk. ${ }^{124}$ Another hypothesis state that low peripheral and central cholesterol can reduce lipid viscosity of neuronal cell membranes, which may decrease exposures of pre-synaptic serotonin transporter or post-synaptic serotonin receptors. ${ }^{125}$ Similarly, further studies should better investigate the role of metabolic (including lipid) profile in determining an increased suicide risk amongst MDD patients, and evaluate how anti-cholesterol and anti-dyslipidemia drugs may reduce suicidality in MDD patients.

\section{Neuropsychological and neurocognitive factors}

Patients with MDD show cognitive deficits in neuropsychological domains, such as visual and verbal memory, working memory, attention, executive function and processing speed, ${ }^{126}$ being the executive functioning impairment the most prominent. ${ }^{127-130}$ More specifically, impairments in cognitive control (i.e., the ability to regulate one's own thoughts and actions in order to achieve internal goals and allows flexible adaptation of behaviour to changing environments), has been strongly associated with MDD-related pathology. ${ }^{131-133}$ Impaired cognitive control abilities have been correlated as well with high suicide rate amongst MDD subjects. ${ }^{128,132-137}$ In fact, neurocognitive deficits are presumed to increase suicide risk as they may determine an incorrect appraisal of one's life situation and an impaired decision-making. ${ }^{133,136}$ One of the neuropsychological domains strongly impaired in MDD regards the executive function, a set of self-regulatory cognitive processes essential for adaptive behaviour. ${ }^{137-143}$ 


\section{Temperament, character and personality traits}

The suicide risk factors implicated in MDD subjects may include distal factors (i.e., those risk factors not strictly related to current episode), such as family history of suicide, early onset of mood disorders, alcohol/substance abuse, adverse early life events, and specific personality traits; as well as proximal factors (i.e., related to current or past mood episode), including hopelessness levels, impulsiveness, SI, severity of current episode within MDD, and recent life events (Table 2). Overall, personality refers to individual features in characteristic patterns of thinking, feeling and consequently behaviours and belong to the stress-diathesis model for suicidal behaviour, being significant influencing factors able to discriminate if a suicidal behaviour emerges within a recrudescence of a psychiatric condition or whether is a situation-oriented process. ${ }^{144}$ In fact, specific personality traits, temperaments and characters may predispose a subject with MDD to develop a SI and/or SA or SC. According to the Cloninger's psychobiological model of temperament and character, ${ }^{145} \mathrm{MDD}$ subjects who had recent SA during a depressive episode exerted different personality profile compared to non-suicidal control group. ${ }^{144}$ In fact, MDD subjects suicide attempters, showed significantly higher scores on harm avoidance (HA) (i.e., a tendency to respond intensely to signals or aversive stimuli) and significantly lower scores in self-directedness (SD), cooperativeness (CO) and persistence (PS) when compared to the non-suicidal group. ${ }^{144} \mathrm{HA}$ is highly heritable temperament dimension linked to the serotonergic system which is in turns altered in suicidal behavior, as abovementioned. SD encompasses personality features like responsibility, self-acceptance, effectiveness; hence, low SD levels have been associated with immaturity, poor self-integration, ineffectiveness and destructiveness which are related to suicidality. ${ }^{145}$ Similarly, the alexithymia construct applied to MDD subjects, seemed to demonstrate a correlation between alexithymia traits, MDD severity and increased risk of SI and more severe SA. ${ }^{146,147}$

\section{Neuroimaging studies}

Neuroimaging studies show changes in several brain areas associated with an increased vulnerability to suicidality. ${ }^{148}$ It has been documented that brain dysfunctions located in temporal, parietal and frontal (specifically dorsolateral and orbitofrontal areas) cortices are described in the suicidal brain. ${ }^{148-154}$ Moreover, three structural areas, e.g., the left superior temporal gyrus, rectal gyrus, caudate nucleus; and three functional areas, e.g., right cingulate gyrus, the anterior cingulate and posterior cingulate have been identified as implicated in an increased suicidal vulnerability. ${ }^{151,155-157} \mathrm{~A}$ smaller volume of the orbitofrontal cortex (right and left), lower left ventrolateral prefrontal cortex (VLPFC), frontal and temporal lobe volumes were observed amongst MDD patients with SA. ${ }^{158-160}$ Reduced grey matter volumes in the frontal, parietal, temporal, insula cortices, left angular gyrus, lentiform nucleus, midbrain, nucleus accumbens, cerebellum have been reported amongst MDD subjects with SA and have been correlated with higher hopelessness levels and lower social support seeking. ${ }^{161-163}$ Right amygdala volumes and lower hippocampal volumes are reported amongst MDD subjects with SA compared to non-suicide attempters. ${ }^{158,160,164}$ Studies carried out on a sample of MDD subjects by using functional magnetic resonance (fMRI) reported a greater resting state functional connectivity in the amygdala, a greater amplitude of low-frequency fluctuation (ALFF) in the right superior temporal gyrus, left middle temporal gyrus and left middle occipital gyrus, whilst a lower ALFF in the left superior frontal gyrus, right ventral medial frontal gyrus and left middle frontal gyrus, amongst MDD subject with SA compared to MDD without SA. ${ }^{165-167}$ Further fMRI studies described a reduced left lateral orbitofrontal cortex (OFC) and occipital cortex activation during risky choices, a higher activation on the left hippocampal and left middle temporal gyrus, amongst MDD with SA. ${ }^{168-170}$ Moreover, a dysfunctional emotion processing neural circuitry has been documented amongst MDD subjects with SA. ${ }^{171}$ In addition, PET studies reported a lower 5-HTT binding in the midbrain, but not in the ventral PFC or the anterior cingulate network, reduced SERT binding potential in the midbrain/pons and putamen, amongst MDD with SA..$^{172,173}$ A SPECT study found reduced SERT binding in the OFC, temporal areas, midbrain, thalamus, basal ganglia and cerebellum of MDD subjects with SA, which in turns are correlated with an increased impulsivity. ${ }^{174}$

\section{DISCUSSION AND CONCLUSION}

Suicide behaviour is highly prevalent amongst patients with $\mathrm{MDD},{ }^{11,175}$ however, depression per se is not a useful tool for a proper understanding of the complexity of suicide, and SI is not a proxy for the diagnosis of MDD. ${ }^{176}$ The uniqueness of each patient determines the variability of the threshold for sustaining mental pain, a condition dependent on personal experiences, emotional states and intimate situation experienced from childhood. ${ }^{175,176}$ Hence, someone could argue that human sadness, most as a reaction to a loss, grief, somewhat crisis, etc., could share features with MDD even in the absence of a validated psychiatric diagnosis..$^{177,178}$ In line with this, the fifth edition of the Diagnostic and Statistical Manual of Mental Disorders (DSM-5) states, "Diagnosis of a mental disorder should have clinical utility" but "the diagnosis of a mental disorder is not equivalent to a need for treatment. Need for treatment is a complex clinical decision that takes 
Table 3. Proposal for suicide risk stratification and recommended interventions

\begin{tabular}{|c|c|}
\hline 'White code'-no suicide risk & \\
\hline $\begin{array}{l}\text { - Absence of SI } \\
\text { - Negative personal and/or family history of suicide, } \\
\text { previous SA } \\
\text { - Symptomatological stability } \\
\text { - Absence of specific suicide risk (Table 1) }\end{array}$ & $\begin{array}{l}\text { - Clinical observation } \\
\text { - Periodic suicide risk evaluation (including the occurrence of new situations, } \\
\text { e.g., the presence of suicide risks before not present) }\end{array}$ \\
\hline 'Green code'-low suicide risk & \\
\hline $\begin{array}{l}\text { - Presence of SI (occasional, inconstant, fleeting, } \\
\text { reported to clinician with scarce credence/conviction } \\
\text { (e.g., with the aim at requesting attention and help; } \\
\text { e.g., present but criticized by the patent in a credible } \\
\text { manner) } \\
\text { - Acute depressive episode in MDD, mild severity } \\
\text { (not stable, not remitted, without comorbid anxiety } \\
\text { and/or mixed symptoms) } \\
\text { - Positive family history of suicide and/or SA in MDD } \\
\text { - Positive personal history of SHB and/or ST } \\
\text { (single and/or recurrent, with low lethality) } \\
\text { - Negative personal history for SA }\end{array}$ & $\begin{array}{l}\text { - Careful and periodic clinical observation by clinicians and all components } \\
\text { of the multi-disciplinary team (i.e., physicians, nurses, psychiatric } \\
\text { rehabilitators, auxiliary staff, psychologists, etc.) of the patient, especially } \\
\text { if he/she is almost silent (and/or he/she does not ask for help/support) } \\
\text { - Actively listen to or support even only with our presence, by ensuring } \\
\text { a peaceful atmosphere and inviting the patient to call and ask for help in } \\
\text { the case he/she may experience negative thoughts } \\
\text { - Developing a good therapeutic alliance and relationship } \\
\text { - Encouraging the expression of thoughts and/or feelings (also negative) } \\
\text { - Providing information and support to patient and his/her family members } \\
\text { regarding the management of a potential emotional crisis and/or instability } \\
\text { and about the alternative coping strategies useful for managing and solving } \\
\text { critical problem(s) } \\
\text { - Carefully observing family, personal and group dynamics and identifying } \\
\text { specific potential trigger factors } \\
\text { - Monitoring and alerting about the occurrence of potential symptoms and/ } \\
\text { or behaviours at risk (e.g., anxiety, agitation, irritability, hypervigilance and/ } \\
\text { or mood instability) } \\
\text { - If possible, do not leave the patient alone (e.g., choose a room with a mate) } \\
\text { - Carefully evaluating the correct intake of medications (do not leave the } \\
\text { medications to patient without checking its assumption) } \\
\text { - Carefully monitoring about personal potentially risky duties }\end{array}$ \\
\hline $\begin{array}{l}\text { 'Yellow code'-moderate suicide risk } \\
\text { - Presence of SI (constant, with low intensity) } \\
\text { - Presence of SI (partially criticized by the patent in a } \\
\text { credible manner) } \\
\text { - Positive and recent personal history of SA without } \\
\text { current SI } \\
\text { - Acute depressive episode in MDD, moderate } \\
\text { severity (not stable, not remitted, with comorbid } \\
\text { anxiety and/or mixed symptoms, without psychotic } \\
\text { symptomatology) }\end{array}$ & $\begin{array}{l}\text { - As for 'green code' plus } \\
\text { - Informing and involving family members } \\
\text { - Providing a personalized supervision and vigilance } \\
\text { - Evaluating the safety of personal duties } \\
\text { (assisting the patient during the use of potential risky objects) } \\
\text { - Eventually, if any, evaluating if changing the room, the position of the bed, } \\
\text { in order to increase the visibility for clinical observation } \\
\text { - Encouraging the patient to objectively evaluate the positive aspects of the } \\
\text { current situation, by analyzing the success experiences (self-motivating statement) } \\
\text { - Correcting his/her sensorial and/or situation/circumstantial wrong perceptions, } \\
\text { without belittle his/her fears and without showing disapproval of his/her convictions } \\
\text { - Limiting frustrating situations if patient is not currently able to express } \\
\text { the anger feeling in a constructed and balanced manner } \\
\text { - Facilitating the expression of anger feelings in a more functional manner } \\
\text { (e.g., sports) } \\
\text { - Stimulating the patient in identifying values of life, the meaning of life, } \\
\text { by doing open-questions, e.g., what do you think it should be your tasks } \\
\text { in your life? Which are your dreams' life? etc. } \\
\text { - Encouraging the patient that 'changing is possible' } \\
\text { - Involving the patient in some positive activity, by facilitating the social interaction } \\
\text { - Encouraging the patient in communicating SI and/or self-harm thoughts } \\
\text { to clinicians } \\
\text { - Identifying potential initial agitation and/or anxiety and/or irritability and/ } \\
\text { or impulsivity }\end{array}$ \\
\hline
\end{tabular}


Table 3. Proposal for suicide risk stratification and recommended interventions (continued)

'Red code'-severe suicide risk

- Positive and recent personal history of SA with active, current and intensive SI

- As for 'green' and 'yellow' code plus

- Providing a more careful and intense clinical supervision and vigilance

- Presence of SI (constant, with high intensity but not criticized by the patent in a credible manner)

(eventually, providing a continuous, $24 \mathrm{~h}$ monitoring of patient)

- Evaluating hospitalization

- Acute depressive episode in MDD, severe severity (not stable, not remitted, with and/or without psychotic symptomatology, e.g., guilt or ruin delusion, with an intense psychomotor agitation, impulsivity, with mixed symptoms, higher introversion levels, with auditory imperative hallucinations of self-harm)

SI: suicide ideation, SA: suicide attempt, ST: suicide threat, SHB: self-harm behaviour, MDD: major depressive disorder

into consideration symptom severity, symptom salience (e.g., the presence of suicidal ideation), the patient's distress (mental pain)" and "Clinicians may thus encounter individuals whose symptoms do not meet full criteria for a mental disorder but who demonstrate a clear need for treatment or care. The fact that some individuals do not show all symptoms indicative of a diagnosis should not be used to justify limiting their access to appropriate care."176,179

The present comprehensive review aimed at investigating only a selection of the myriad of suicide risk factors supposed to be implicated in the suicidality amongst MDD subjects. Overall, suicidality is indeed a highly complex and multifaceted phenomenon in which a large plethora of mechanisms and processes could be variable implicated, including the dysregulation of HPA activity, genetic load, epigenetics, cholesterol and triglyceride profile, specific neurocognitive and neuropsychological impaired domains, some personality traits and characters, sometimes state-dependent, and so on. $8,23,41,43,65,78,110,112,114,128,130,144,145,148,150,175,176$ However, somewhat contrasting and sometimes inconclusive findings have been so far published, by enlarging the plethora of research fields yet to be furtherly deepened and investigated in the field of suicide risk amongst MDD subjects. As abovementioned, great deal of research has focused on dysfunction of the HPA axis and on alterations of main neurotransmitter system as well as a set of neuro-inflammatory modulators, even though concluding findings are still unclear. ${ }^{14,55-60}$ Indeed, the recently investigated and interesting role of glutamatergic involvement may play a significant role, given recent antisuicidal findings with NMDA antagonist esketamine. ${ }^{180,181}$ Further evidences appear to emerge at the genetic and epigenetic level, with a series of supposed proximal and distal suicide risk factors associated with various endophenotypes implicated in suicidality amongst MDD subjects. ${ }^{19-54}$ Therefore, assessing suicidality amongst MDD subjects requires a multidimensional approach, which takes into account suicidality factors at every level, preclinical, neurobiological, neurochemical, clinical and psychopathological. Overall, key suicide and protective risk factors amongst patients with MDD have been clearly recognized and analyzed (Table 2). However, one could argue that SA would be indeed different with CS, regarding a suicide risk stratification as it reflects a different underpinning biological mechanism. Indeed, the most significant predictors of CS appeared to be represented by the presence of a history of previous SA, reaching an odds ratio (OR) of around 4.84. ${ }^{182}$ Therefore, the identification of a range of suicide risk factors, particularly regarding a previous (family and personal) history of SA is clinically relevant for clinicians and should be always considered for preventing CS amongst MDD patients. Beyond these consideration, modern psychiatry needs a better interpretation of suicide risk with a more careful assessment of suicide risk stratification and planning of clinical and treatment interventions, particularly amongst special population. ${ }^{183,184}$ Therefore, authors here propose a stratification model of suicide risk accompanied with a list of suggested recommendations regarding interventions and treatments to be planned, useful for clinical practice, particularly for those working in Mental Health (Table 3).

\section{Acknowledgments}

None.

\section{Conflicts of Interest}

The authors have no potential conflicts of interest to disclose.

\section{Author Contributions}

All authors have contributed to the present reviwe with equal efforts.

\section{ORCID iDs}

Laura Orsolini

Maurizio Pompili

Gianluca Serafini

Umberto Volpe

Federica Vellante

Michele Fornaro https://orcid.org/0000-0002-6882-3770 https://orcid.org/0000-0003-1886-4977 https://orcid.org/0000-0002-6631-856X https://orcid.org/0000-0001-9166-7609 https://orcid.org/0000-0002-4844-5688 https://orcid.org/0000-0002-9647-0853 
Carmine Tomasetti Giovanni Martinotti Massimo Di Giannantonio Domenico De Berardis

https://orcid.org/0000-0002-3130-6569 https://orcid.org/0000-0002-7292-2341 https://orcid.org/0000-0001-9681-8058 https://orcid.org/0000-0003-4415-5058

\section{REFERENCES}

1. Bertolote JM, Fleischmann A. A global perspective in the epidemiology of suicide. Suicidology 2002;7:6-8.

2. Hawton K, van Heeringen K. Suicide. Lancet 2009;373:1372-1381.

3. WHO. Mental Health Atlas 2017. Geneva: World Health Organization; 2018. Available at: https://apps.who.int/iris/bitstream/hand le/10665/272735/9789241514019-eng.pdf?ua=1. Accessed June 10, 2019.

4. Stone DM, Holland KM, Bartholow B, Crosby AE, Davis S, Wilkins N. Preventing Suicide: A Technical Package of Policies, Programs, and Practices. Atlanta, GA: National Center for Injury Prevention and Control, Centers for Disease Control and Prevention; 2017. Available at: https://www.cdc.gov/violenceprevention/pdf/suicideTechnicalPackage.pdf. Accessed June 10, 2019.

5. Chesney E, Goodwin GM, Fazel S. Risks of all-cause and suicide mortality in mental disorders: a meta-review. World Psychiatry 2014;13:153-160.

6. Andrade L, Caraveo-anduaga JJ, Berglund P, Bijl RV, Graaf RD, Vollebergh W, et al. The epidemiology of major depressive episodes: results from the International Consortium of Psychiatric Epidemiology (ICPE) Surveys. Int J Methods Psychiatr Res 2003;12:3-21.

7. Schmidt HD, Shelton RC, Duman RS. Functional biomarkers of depression: diagnosis, treatment, and pathophysiology. Neuropsychopharmacology 2011;36:2375-2394.

8. Ferrari AJ, Somerville AJ, Baxter AJ, Norman R, Patten SB, Vos T, et al. Global variation in the prevalence and incidence of major depressive disorder: a systematic review of the epidemiological literature. Psychol Med 2013;43:471-481.

9. Mann JJ. A current perspective of suicide and attempted suicide. Ann Intern Med 2002;136:302-311.

10. Coryell W, Young EA. Clinical predictors of suicide in primary major depressive disorder. J Clin Psychiatry 2005;66:412-417.

11. Ponsoni A, Branco LD, Cotrena C, Shansis FM, Grassi-Oliveira R, Fonseca RP. Self-reported inhibition predicts history of suicide attempts in bipolar disorder and major depression. Compr Psychiatry 2018;82:89-94.

12. Pfeiffer PN, Ganoczy D, Ilgen M, Zivin K, Valenstein M. Comorbid anxiety as a suicide risk factor among depressed veterans. Depress Anxiety 2009;26:752-757.

13. Abreu LN, Oquendo MA, Galfavy H, Burke A, Grunebaum MF, Sher $\mathrm{L}$, et al. Are comorbid anxiety disorders a risk factor for suicide attempts in patients with mood disorders? A two-year prospective study. Eur Psychiatry 2018;47:19-24.

14. Pompili M, Serafini G, Innamorati M, Möller-Leimkühler AM, Giupponi G, Girardi P, et al. The hypothalamic-pituitary-adrenal axis and serotonin abnormalities: a selective overview for the implications of suicide prevention. Eur Arch Psychiatry Clin Neurosci 2010;260:583600.

15. Lee BH, Kim YK. The roles of BDNF in the pathophysiology of major depression and in antidepressant treatment. Psychiatry Investig 2010;7:231-235.

16. Van Heeringen K, Mann JJ. The neurobiology of suicide. Lancet Psychiatry 2014;1:63-72.

17. Centers for Disease Control and Prevention (CDC). Suicide rising across the US More than a mental health concern. Available at: https://www.cdc.gov/vitalsigns/suicide/index.html. Accessed June 10, 2019.

18. Eikelenboom M, Beekman ATF, Penninx BWJH, Smit JH. A 6-year longitudinal study of predictors for suicide attempts in major depres- sive disorder. Psychol Med 2019;49:911-921.

19. Brent DA, Mann JJ. Family genetic studies, suicide, and suicidal behavior. Am J Med Genet Part C. Semin Med Genet 2005;133C:13-24.

20. Statham DJ, Heath AC, Madden PA, Bucholz KK, Bierut L, Dinwiddie $\mathrm{SH}$, et al. Suicidal behaviour: an epidemiological and genetic study. Psychol Med 1998;28:839-855.

21. Glowinski AL, Bucholz KK, Nelson EC, Fu Q, Madde PF, Reich W, et al. Suicide attempts in an adolescent female twin sample. J Am Acad Child Adolesc Psychiatry 2001;40:1300-1307.

22. Fu Q, Heath AC, Bucholz KK, Nelson EC, Glowinski AL, Goldberg J, et al. A twin study of genetic and environmental influences on suicidality in men. Psychol Med 2002;32:11-24.

23. Voracek M, Loibl LM. Genetics of suicide: a systematic review of twin studies. Wien Klin Wochenschr 2007;119:463-475.

24. Brent DA, Melhem N. Familial transmission of suicidal behavior. Psychiatr Clin North Am 2008;31:157-177.

25. Tidemalm D, Runeson B, Waern M, Frisell T, Carlström E, Lichtenstein $\mathrm{P}$, et al. Familial clustering of suicide risk: a total population study of 11.4 million individuals. Psychol Med 2011;41:2527-2534.

26. Schosser A, Butler AW, Ising M, Perroud N, Uher R, Ng MY, et al. Genomewide association scan of suicidal thoughts and behaviour in major depression. PLoS One 2011;6:e20690.

27. Willour VL, Seifuddin F, Mahon PB, Jancic D, Pirooznia M, Steele J, et al. A genome-wide association study of attempted suicide. Mol Psychiatry 2012;17:433-444.

28. Mullins N, Perroud N, Uher R, Butler AW, Cohen-Woods S, Rivera $\mathrm{M}$, et al. Genetic relationships between suicide attempts, suicidal ideation and major psychiatric disorders: a genome-wide association and polygenic scoring study. Am J Med Genet B Neuropsychiatr Genet 2014;165B:428-437.

29. Galfalvy H, Haghighi F, Hodgkinson C, Goldman D, Oquendo MA, Burke A, et al. A genome-wide association study of suicidal behavior. Am J Med Genet B Neuropsychiatr Genet 2015;168:557-563.

30. Stein MB, Ware EB, Mitchell C, Chen CY, Borja S, Cai T, et al. Genomewide association studies of suicide attempts in US soldiers. Am J Med Genet B Neuropsychiatr Genet 2017;174:786-797.

31. Mullins N, Bigdeli TB, Børglum AD, Coleman JRI, Demontis D, Mehta D, et al. GWAS of suicide attempt in psychiatric disorders and association with major depression polygenic risk scores. Am J Psychiatry 2019;176:651-660.

32. Butler AW, Breen G, Tozzi F, Craddock N, Gill M, Korszun A, et al. A genomewide linkage study on suicidality in major depressive disorder confirms evidence for linkage to 2p12. Am J Med Genet B Neuropsychiatr Genet 2010;153B:1465-1473.

33. Erlangsen A, Appadurai V, Wang Y, Turecki G, Mors O, Werge T, et al. Genetics of suicide attempts in individuals with and without mental disorders: a population-based genome-wide association study. Mol Psychiatry 2018 [Epub ahead of print].

34. Ruderfer DM, Walsh CG, Aguirre MW, Tanigawa Y, Ribeiro JD, Franklin JC, et al. Significant shared heritability underlies suicide attempt and clinically predicted probability of attempting suicide. Mol Psychiatry 2019 [Epub ahead of print].

35. Hirata T, Otsuka I, Okazaki S, Mouri K, Horai T, Boku S, et al. Major depressive disorder-associated SIRT1 locus affects the risk for suicide in women after middle age. Psychiatry Res 2019;278:141-145.

36. Binder EB. The role of FKBP5, a co-chaperone of the glucocorticoid receptor in the pathogenesis and therapy of affective and anxiety disorders. Psychoneuroendocrinology 2009;34(Suppl 1):S186-S195.

37. Fries GR, Gassen NC, Rein T. The FKBP51 Glucocorticoid receptor co-chaperone: regulation, function, and implications in health and disease. Int J Mol Sci 2017;18(12). pii: E2614.

38. Zannas AS, Wiechmann T, Gassen NC, Binder EB. Gene-stress-epigenetic regulation of fkbp5: clinical and translational implications. Neuropsychopharmacology 2016;41:261-274

39. Appel K, Schwahn C, Mahler J, Schulz A, Spitzer C, Fenske K, et al. 
Moderation of adult depression by a polymorphism in the FKBP5 gene and childhood physical abuse in the general population. Neuropsychopharmacology 2011;36:1982-1991.

40. Kohrt BA, Worthman CM, Ressler KJ, Mercer KB, Upadhaya N, Koirala $\mathrm{S}$, et al. Cross-cultural gene- environment interactions in depression, post-traumatic stress disorder, and the cortisol awakening response: FKBP5 polymorphisms and childhood trauma in South Asia. Int Rev Psychiatry 2015;27:180-196.

41. Tozzi L, Carballedo A, Wetterling F, McCarthy H, O’Keane V, Gill M, et al. Single-nucleotide polymorphism of the fkbp5 gene and childhood maltreatment as predictors of structural changes in brain areas involved in emotional processing in depression. Neuropsychopharmacology 2016;41:487-497.

42. Yeo S, Enoch MA, Gorodetsky E, Akhtar L, Schuebel K, Roy A, et al. The influence of FKBP5 genotype on expression of FKBP5 and other glucocorticoidregulated genes, dependent on trauma exposure. Genes Brain Behav 2017;16:223-232.

43. Hernández-Díaz Y, González-Castro TB, Tovilla-Zárate CA, JuárezRojop IE, López-Narváez ML, Pérez-Hernández N, et al. Association between FKBP5 polymorphisms and depressive disorders or suicidal behavior: a systematic review and meta-analysis study. Psychiatry Res 2019;271:658-668.

44. Gonda X, Fountoulakis KN, Harro J, Pompili M, Akiskal HS, Bagdy $\mathrm{G}$, et al. The possible contributory role of the $\mathrm{S}$ allele of 5-HTTLPR in the emergence of suicidality. J Psychopharmacol 2011;25:857-866.

45. Antypa N, Serretti A, Rujescu D. Serotonergic genes and suicide: a systematic review. Eur Neuropsychopharmacol 2013;23:1125-1142.

46. Daws LC, Toney GM. High-Speed Chronoamperometry to Study Kinetics and Mechanisms for Serotonin Clearance in Vivo. In: Michael AC, Borland LM, Editors. Electrochemical Methods for Neuroscience. Florida: Boca Raton, 2007, p.63-81.

47. Purselle DC, Nemeroff CB. Serotonin transporter: a potential substrate in the biology of suicide. Neuropsychopharmacology 2003;28:613-619.

48. Levey DF, Polimanti R, Cheng Z, Zhou H, Nuñez YZ, Jain S, et al. Genetic associations with suicide attempt severity and genetic overlap with major depression. Transl Psychiatry 2019;9:22.

49. Fanelli G, Serretti A. The influence of the serotonin transporter gene 5-HTTLPR polymorphism on suicidal behaviors: a meta-analysis. Prog Neuropsychopharmacol Biol Psychiatry 2019;88:375-387.

50. Ludwig B, Roy B, Wang Q, Birur B, Dwivedi Y. The life span model of suicide and its neurobiological foundation. Front Neurosci 2017;11:74.

51. Turecki G, Ernst C, Jollant F, Labonté B, Mechawar N. The neurodevelopmental origins of suicidal behavior. Trends Neurosci 2012;35:14-23.

52. Booij L, Wang D, Lévesque ML, Tremblay RE, Szyf M. Looking beyond the DNA sequence: the relevance of DNA methylation processes for the stress-diathesis model of depression. Philos Trans R Soc Lond B Biol Sci 2013;368:20120251.

53. Brown A, Fiori LM, Turecki G. Bridging basic and clinical research in early life adversity, DNA methylation, and major depressive disorder. Front Genet 2019;10:229.

54. Roy B, Shelton RC, Dwivedi Y. DNA methylation and expression of stress related genes in PBMC of MDD patients with and without serious suicidal ideation. J Psychiatr Res 2017;89:115-124.

55. Duman RS, Heninger GR, Nestler EJ. A molecular and cellular theory of depression. Arch Gen Psychiatry 1997;54:597-606.

56. Arato M, Banki CM, Bissette G, Nemeroff CB. Elevated CSF CRF in suicide victims. Biol Psychiatry 1989;25:355-359.

57. Coryell W, Schlesser M. The dexamethasone suppression test and suicide prediction. Am J Psychiatry 2001;158:748-753.

58. Kunugi H, Urushibara T, Nanko S. Combined DEX/CRH test among Japanese patients with major depression. J Psychiatr Res 2004;38:123128.

59. Yerevanian BI, Feusner JD, Koek RJ, Mintz J. The dexamethasone suppression test as a predictor of suicidal behavior in unipolar depression. J Affect Disord 2004;83:103-108.
60. Jokinen J, Nordström AL, Nordström P. ROC analysis of dexamethasone suppression test threshold in suicide prediction after attempted suicide. J Affect Disord 2008;106:145-152.

61. Underwood MD, Khaibulina AA, Ellis SP, Moran A, Rice PM, Mann JJ, et al. Morphometry of the dorsal raphe nucleus serotonergic neurons in suicide victims. Biol Psychiatry 1999;46:473-483.

62. Boldrini M, Underwood MD, Mann JJ, Arango V. More tryptophan hydroxylase in the brainstem dorsal raphe nucleus in depressed suicides. Brain Res 2005;1041:19-28.

63. Bonkale WL, Turecki G, Austin MC. Increased tryptophan hydroxylase immunoreactivity in the dorsal raphe nucleus of alcohol-dependent, depressed suicide subjects is restricted to the dorsal subnucleus. Synapse 2006;60:81-5.

64. Asberg M, Traskman L, Thoren P. 5-HIAA in the cerebrospinal fluid. A biochemical suicide predictor? Arch Gen Psychiatry 1976;33:11931197.

65. Mann JJ, Arango V, Marzuk PM, Theccanat S, Reis DJ. Evidence for the 5-HT hypothesis of suicide. A review of post-mortem studies. $\mathrm{Br}$ J Psychiatry Suppl 1989:(8);7-14.

66. Mann JJ, Huang YY, Underwood MD, Kassir SA, Oppenheim S, Kelly TM, et al. A serotonin transporter gene promoter polymorphism (5-HTTLPR) and prefrontal cortical binding in major depression and suicide. Arch Gen Psychiatry 2000;57:729-738.

67. Hou C, Jia F, Liu Y, Li L. CSF serotonin, 5-hydroxyindolacetic acid and neuropeptide $\mathrm{Y}$ levels in severe major depressive disorder. Brain Res 2006;1095:154-158.

68. Leake A, Fairbairn AF, McKeith IG, Ferrier IN. Studies on the serotonin uptake binding site in major depressive disorder and control post-mortem brain: neurochemical and clinical correlates. Psychiatry Res 1991;39:155-165.

69. Arango V, Ernsberger P, Marzuk PM, Chen JS, Tierney H, Stanley M, et al. Autoradiographic demonstration of increased serotonin 5-HT2 and beta-adrenergic receptor binding sites in the brain of suicide victims. Arch Gen Psychiatry 1990;47:1038-1047.

70. Pandey GN, Dwivedi Y, Rizavi HS, Ren X, Pandey SC, Pesold C, et al. Higher expression of serotonin 5-HT(2A) receptors in the postmortem brains of teenage suicide victims. Am J Psychiatry 2002;159:419429.

71. Mann JJ, Currier D, Stanley B, Oquendo MA, Amsel LV, Ellis SP. Can biological tests assist prediction of suicide in mood disorders? Int J Neuropsychopharmacol 2006;9:465-474.

72. Gaysina D, Zainullina A, Gabdulhakov R, Khusnutdinova E. The serotonin transporter gene: polymorphism and haplotype analysis in Russian suicide attempters. Neuropsychobiology 2006;54:70-74.

73. Agargun MY, Cartwright R. REM sleep, dream variables and suicidality in depressed patients. Psychiatry Res 2003;119:33-39.

74. Singareddy RK, Balon R. Sleep and suicide in psychiatric patients. Ann Clin Psychiatry 2001;13:93-101.

75. Chen B, Dowlatshahi D, MacQueen GM, Wang JF, Young LT. Increased hippocampal BDNF immunoreactivity in subjects treated with antidepressant medication. Biol Psychiatry 2001;50:260-265.

76. Chen YY, Lu TH. Suicide prevention is not just about treating depression. Inj Prev 2006;12:208.

77. Grah M, Mihanovic M, Ruljancic N, Restek-Petrovic B, Molnar S, Jelavic S. Brain-derived neurotrophic factor as a suicide factor in mental disorders. Acta Neuropsychiatr 2014;26:356-363.

78. Eisen RB, Perera S, Banfield L, Anglin R, Minuzzi L, Samaan Z. Association between BDNF levels and suicidal behaviour: a systematic review and meta-analysis. Syst Rev 2015;4:187.

79. Eisen RB, Perera S, Bawor M, Dennis BB, El-Sheikh W, DeJesus J, et al. Exploring the association between serum BDNF and attempted suicide. Sci Rep 2016;6:25229.

80. Castren E, Kojima M. Brain-derived neurotrophic factor in mood disorders and antidepressant treatments. Neurobiol Dis 2017;97:119126. 
81. Duman RS, Monteggia LM. A neurotrophic model for stress-related mood disorders. Biol Psychiatry 2006;59:1116-1127.

82. Huang TL, Lee CT. Associations between serum brain-derived neurotrophic factor levels and clinical phenotypes in schizophrenia patients. J Psychiatr Res 2006;40:664-668.

83. Dwivedi Y. Brain-Derived Neurotrophic Factor in Suicide Pathophysiology. The Neurobiological Basis of Suicide. Florida: Boca Raton (FL); 2012.

84. Garcia R. Stress, synaptic plasticity, and psychopathology. Rev Neurosci 2002;13:195-208.

85. Wagner G, Schultz CC, Koch K, Schachtzabel C, Sauer H, Schlosser RG. Prefrontal cortical thickness in depressed patients with high-risk for suicidal behavior. J Psychiatr Res 2012;46:1449-1455.

86. Sher L. Brain-derived neurotrophic factor and suicidal behavior. QJM 2011;104:455-458.

87. Paska AV, Zupanc T, Pregelj P. The role of brain-derived neurotrophic factor in the pathophysiology of suicidal behavior. Psychiatr Danub 2013;25(Suppl 2):S341-S344.

88. Lee BH, Kim YK. Potential peripheral biological predictors of suicidal behavior in major depressive disorder. Prog Neuropsychopharmacol Biol Psychiatry 2011;35:842-847.

89. Kim YK, Lee HP, Won SD, Park EY, Lee HY, Lee BH, et al. Low plasma BDNF is associated with suicidal behavior in major depression. Prog Neuropsychopharmacol Biol Psychiatry 2007;31:78-85.

90. Khan MS, Wu GWY, Reus VI, Hough CM, Lindqvist D, Westrin Å, et al. Low serum brain-derived neurotrophic factor is associated with suicidal ideation in major depressive disorder. Psychiatry Res 2019; 273:108-113.

91. Duman RS, Malberg J, Thome J. Neural plasticity to stress and antidepressant treatment. Biol Psychiatry 1999;46:1181-1191.

92. Manji HK, Drevets WC, Charney DS. The cellular neurobiology of depression. Nat Med 2001;7:541-547.

93. Neves-Pereira M, Mundo E, Muglia P, King N, Macciardi F, Kennedy JL. The brain-derived neurotrophic factor gene confers susceptibility to bipolar disorder: evidence from a family-based association study. Am J Hum Genet 2002;71:651-655.

94. Sklar P, Gabriel SB, McInnis MG, Bennett P, Lim Y, Tsan G, et al. Family-based association study of 76 candidate genes in bipolar disorder: BDNF is a potential risk locus. Brain-derived neutrophic factor. Mol Psychiatry 2002;7:579-593.

95. Egan MF, Kojima M, Callicott JH, Goldberg TE, Kolachana BS, Bertolino A, et al. The BDNF val66met polymorphism affects activitydependent secretion of BDNF and human memory and hippocampal function. Cell 2003;112:257-269.

96. Dowlatshahi D, MacQueen GM, Wang JF, Reiach JS, Young LT. G Protein-coupled cyclic AMP signaling in postmortem brain of subjects with mood disorders: effects of diagnosis, suicide, and treatment at the time of death. J Neurochem 1999;73:1121-1126.

97. Dwivedi Y, Rao JS, Rizavi HS, Kotowski J, Conley RR, Roberts RC, et al. Abnormal expression and functional characteristics of cyclic adenosine monophosphate response element binding protein in postmortem brain of suicide subjects. Arch Gen Psychiatry 2003;60:273-282.

98. Young LT, Bezchlibnyk YB, Chen B, Wang JF, MacQueen GM. Amygdala cyclic adenosine monophosphate response element binding protein phosphorylation in patients with mood disorders: effects of diagnosis, suicide, and drug treatment. Biol Psychiatry 2004;55:570-577.

99. Carlberg L, Schosser A, Calati R, Serretti A, Massat I, Papageorgiou $\mathrm{K}$, et al. Association study of CREB1 polymorphisms and suicidality in MDD: results from a European multicenter study on treatment resistant depression. Int J Neurosci 2015;125:336-343.

100. Martino M, Rocchi G, Escelsior A, Contini P, Colicchio S, de Berardis D, et al. NGF serum levels variations in major depressed patients receiving duloxetine. Psychoneuroendocrinology 2013;38:1824-1828.

101. Banerjee R, Ghosh AK, Ghosh B, Bhattacharyya S, Mondal AC. Decreased mRNA and protein expression of BDNF, NGF, and their re- ceptors in the hippocampus from suicide: an analysis in human postmortem brain. Clin Med Insights Pathol 2013;6:1-11.

102. Dwivedi Y, Mondal AC, Rizavi HS, Conley RR. Suicide brain is associated with decreased expression of neurotrophins. Biol Psychiatry 2005;58:315-324.

103. Diniz BS, Teixeira AL, Machado-Vieira R, Talib LL, Gattaz WF, Forlenza OV. Reduced serum nerve growth factor in patients with latelife depression. Am J Geriat Psychiatry 2013;21:493-496.

104. Wiener CD, de Mello Ferreira S, Pedrotti Moreira F, Bittencourt G, de Oliveira JF, Lopez Molina M, et al. Serum levels of nerve growth factor (NGF) in patients with major depression disorder and suicide risk. J Affect Disord 2015;184:245-248.

105. Serafini G, Pompili M, Elena Seretti M, Stefani H, Palermo M, Coryell W, et al. The role of inflammatory cytokines in suicidal behavior: a systematic review. Eur Neuropsychopharmacol 2013;23:1672-1686.

106. Black C, Miller BJ. Meta-analysis of cytokines and chemokines in suicidality: distinguishing suicidal versus nonsuicidal patients. Biol Psychiatry 2015;78:28-37.

107. Courtet P, Giner L, Seneque M, Guillaume S, Olie E, Ducasse D. Neuroinflammation in suicide: toward a comprehensive model. World J Biol Psychiatry 2016;17:564-586.

108. Gabbay V, Klein RG, Guttman LE, Babb JS, Alonso CM, Nishawala $\mathrm{M}$, et al. A preliminary study of cytokines in suicidal and nonsuicidal adolescents with major depression. J Child Adolesc Psychopharmacol 2009;19:423-430.

109. Vargas HO, Nunes SO, Pizzo de Castro M, Bortolasci CC, Sabbatini Barbosa D, Kaminami Morimoto H, et al. Oxidative stress and lowered total antioxidant status are associated with a history of suicide attempts. J Affect Disord 2013;150:923-930.

110. Marini S, Vellante F, Matarazzo I, De Berardis D, Serroni N, Gianfelice $\mathrm{D}$, et al. Inflammatory markers and suicidal attempts in depressed patients: A review. Int J Immunopathol Pharmacol 2016;29:583-594.

111. Frick MH, Elo O, Haapa K, Heinonen OP, Heinsalmi P, Helo P, et al. Helsinki Heart Study: primary-prevention trial with gemfibrozil in middle-aged men with dyslipidemia. Safety of treatment, changes in risk factors, and incidence of coronary heart disease. N Engl J Med 1987;317:1237-1245.

112. Muldoon MF, Manuck SB, Matthews KA. Lowering cholesterol concentrations and mortality: a quantitative review of primary prevention trials. BMJ 1990;301:309-314.

113. De Berardis D, Conti CM, Serroni N, Moschetta FS, Carano A, Salerno RM, et al. The role of cholesterol levels in mood disorders and suicide. J Biol Regul Homeost Agents 2009;23:133-140.

114. De Berardis D, Marini S, Piersanti M, Cavuto M, Perna G, Valchera $\mathrm{A}$, et al. The relationships between cholesterol and suicide: an update. ISRN Psychiatry 2012;2012:387901

115. Segoviano-Mendoza M, Cárdenas-de la Cruz M, Salas-Pacheco J, Vázquez-Alaniz F, La Llave-León O, Castellanos-Juárez F, et al. Hypocholesterolemia is an independent risk factor for depression disorder and suicide attempt in Northern Mexican population. BMC Psychiatry 2018;18:7.

116. Kunugi H, Takei N, Aoki H, Nanko S. Low serum cholesterol in suicide attempters. Biol Psychiatry 1997;41:196-200.

117. Papassotiropoulos A, Hawellek B, Frahnert C, Rao GS, Rao M. The risk of acute suicidality in psychiatric inpatients increases with low plasma cholesterol. Pharmacopsychiatry 1999;32:1-4.

118. Alvarez JC, Cremniter D, Gluck N, Quintin P, Leboyer M, Berlin I, et al. Low serum cholesterol in violent but not in non-violent suicide attempters. Psychiatry Res 2000;95:103-108.

119. Kim YK, Lee HJ, Kim JY, Yoon DK, Choi SH, Lee MS. Low serum cholesterol is correlated to suicidality in a Korean sample. Acta Psychiatr Scand 2002;105:141-148.

120. Lee HJ, Kim YK. Serum lipid levels and suicide attempts. Acta Psychiatr Scand 2003;108:215-221.

121. Misiak B, Stanczykiewicz B, Laczmanski L, Frydecka D. Lipid profile 
disturbances in antipsychotic-naive patients with first-episode nonaffective psychosis: a systematic review and meta-analysis. Schizophr Res 2017;190:18-27.

122. Vuksan-Cusa B, Marcinko D, Nad S, Jakovljevic M. Differences in cholesterol and metabolic syndrome between bipolar disorder men with and without suicide attempts. Acta Neuropsychiatr 2009;21(Suppl 2):66-69.

123. Da Graca Cantarelli M, Nardin P, Buffon A, Eidt MC, Antonio Godoy L, Fernandes BS, et al. CA. Serum triglycerides, but not cholesterol or leptin, are decreased in suicide attempters with mood disorders. J Affect Disord 2015;172:403-409.

124. Budania S, Rathi M, Singh S, Yadav S, Mittra P. Serum cholesterol and depression: an update. Med J 2014;7:543-549.

125. Wallner B, Machatschke IH. The evolution of violence in men: the function of central cholesterol and serotonin. Prog Neuropsychopharmacol Biol Psychiatry 2009;33:391-397.

126. Rock PL, Roiser JP, Riedel WJ, Blackwell AD. Cognitive impairment in depression: a systematic review and meta-analysis. Psychol Med 2014; 44:2029-2040.

127. Austin MP, Mitchell P, Goodwin GM. Cognitive deficits in depression: possible implications for functional neuropathology. Br J Psychiatry 2001;178:200-206.

128. Marzuk PM, Hartwell N, Leon AC, Portera L. Executive functioning in depressed patients with suicidal ideation. Acta Psychiatr Scand 2005;112:294-301.

129. Hammar A, Ardal G. Cognitive functioning in major depression-a summary. Front Hum Neurosci 2009;3:26.

130. Pu S, Setoyama S, Noda T. Association between cognitive deficits and suicidal ideation in patients with major depressive disorder. Sci Rep 2017;7:11637.

131. Braver TS. The variable nature of cognitive control: a dual mechanisms framework. Trends Cogn Sci 2012;16:106-113.

132. Paulus MP. Cognitive control in depression and anxiety: out of control? Current Opinion in Behavioral Sciences 2015;1:113-120.

133. McGirr A, Dombrovski AY, Butters MA, Clark L, Szanto K. Deterministic learning and attempted suicide among older depressed individuals: cognitive assessment using the Wisconsin Card Sorting Task. J Psychiatr Res 2012;46:226-232.

134. Westheide J, Quednow BB, Kuhn KU, Hoppe C, Cooper-Mahkorn D, Hawellek B, et al. Executive performance of depressed suicide attempters: the role of suicidal ideation. Eur Arch Psychiatry Clin Neurosci 2008;258:414-421.

135. Huang H, Movellan J, Paulus MP, Harle KM. The influence of depression on cognitive control: disambiguating approach and avoidance tendencies. PLoS One 2015;10:e0143714.

136. Gorlyn M, Keilp J, Burke A, Oquendo M, Mann JJ, Grunebaum M. Treatment-related improvement in neuropsychological functioning in suicidal depressed patients: paroxetine vs. bupropion. Psychiatry Res 2015;225:407-412.

137. Richard-Devantoy S, Berlim M, Jollant F. A meta-analysis of neuropsychological markers of vulnerability to suicidal behavior in mood disorders. Psychol Med 2014;44:1663-1673.

138. Keilp JG, Sackeim HA, Brodsky BS, Oquendo MA, Malone KM, Mann JJ. Neuropsychological dysfunction in depressed suicide attempters. Am J Psychiatry 2001;158:735-741.

139. Roiser JP, Sahakian BJ. Hot and cold cognition in depression. CNS spectrums 2013;18:139-149.

140. Snyder HR. Major depressive disorder is associated with broad impairments on neuropsychological measures of executive function: a meta-analysis and review. Psychol Bull 2013;139:81-132.

141. Bortolato B, Carvalho AF, McIntyre RS. Cognitive dysfunction in major depressive disorder: a state-of-the-art clinical review. CNS Neurolog Disorders Drug Targets 2014;13:1804-1818.

142. Snyder HR, Miyake A, Hankin BL. Advancing understanding of executive function impairments and psychopathology: bridging the gap between clinical and cognitive approaches. Front Psychol
2015;6:328.

143. Ho MC, Hsu YC, Lu ML, Gossop M, Chen VC. 'Cool' and 'Hot' executive functions in suicide attempters with major depressive disorder. J Affect Disord 2018;235:332-340.

144. Erić AP, Erić I, Curković M, Dodig-Ćurković K, Kralik K, Kovač V, et al. The temperament and character traits in patients with major depressive disorder and bipolar affective disorder with and without suicide attempt. Psychiatr Danub 2017;29:171-178.

145. Cloninger CR, Svrakic DM, Przybeck TR. A psychobiological model of temperament and character. Arch Gen Psychiatry 1993;50:975990.

146. De Berardis D, Fornaro M, Orsolini L, Valchera A, Carano A, Vellante $\mathrm{F}$, et al. Alexithymia and suicide risk in psychiatric disorders: a mini-review. Front Psychiatry 2017;8:148.

147. De Berardis D, Olivieri L, Rapini G, Di Natale S, Serroni N, Fornaro $\mathrm{M}$, et al. Alexithymia, suicide ideation and homocysteine levels in drug naïve patients with major depression: a study in the "real world" clinical practice. Clin Psychopharmacol Neurosci 2019;17:318-322.

148. Bani-Fatemi A, Tasmim S, Graff-Guerrero A, Gerretsen P, Strauss J, Kolla N, et al. Structural and functional alterations of the suicidal brain: An updated review of neuroimaging studies. Psychiatry Res Neuroimaging 2018;278:77-91.

149. Desmyter S, van Heeringen C, Audenaert K. Structural and functional neuroimaging studies of the suicidal brain. Prog Neuropsychopharmacol Biol Psychiatry 2011;35:796-808.

150. Jollant F, Lawrence NL, Olié E, Guillaume S, Courtet P. The suicidal mind and brain: a review of neuropsychological and neuroimaging studies. World J Biol Psychiatry 2011;12:319-339.

151. Van Heeringen K, Bijttebier S, Desmyter S, Vervaet M, Baeken C. Is there a neuroanatomical basis of the vulnerability to suicidal behavior? A coordinate-based meta-analysis of structural and functional MRI studies. Front Hum Neurosci 2014;22:824.

152. Cox Lippard ET, Johnston JAY, Blumberg HP. Neurobiological risk factors for suicide: insights from brain imaging. Am J Prev Med 2014; 47:S152-S162.

153. Zhang H, Chen Z, Jia Z, Gong Q. Dysfunction of neural circuitry in depressive patients with suicidal behaviors: a review of structural and functional neuroimaging studies. Prog Neuropsychopharmacol Biol Psychiatry 2014;53:61-66.

154. Jollant F. Neuroimaging of Suicidal Behavior. In: Kaschka WP, Rujescu D, Editors. Biological Aspects of Suicidal Behavior. Adv Biol Psychiatry. Basel: Karger, 2016, p.110-122.

155. Vang FJ, Ryding E, Träskman-Bendz L, van Westen D, Lindström MB. Size of basal ganglia in suicide attempters, and its association with temperament and serotonin transporter density. Psychiatry Res 2010;183:177-179.

156. Dombrovski AY, Siegle GJ, Szanto K, Clark L, Reynolds CF, Aizenstein $\mathrm{H}$. The temptation of suicide: striatal gray matter, discounting delayed rewards, and suicide attempts in late-life depression. Psychol Med 2012;42:1203-1215.

157. Peng H, Wu K, Li J, Qi H, Guo S, Chi M, et al. Increased suicide attempts in young depressed patients with abnormal temporal-parietal-limbic gray matter volume. J Affect Disord 2014;165:69-73.

158. Monkul ES, Hatch JP, Nicoletti MA, Spence S, Brambilla P, Lacerda $\mathrm{AL}$, et al. Fronto-limbic brain structures in suicidal and non-suicidal female patients with major depressive disorder. Mol Psychiatry 2007; 12:360-366.

159. Ding Y, Lawrence N, Olié E, Cyprien F, le Bars E, Bonafé A, et al. Prefrontal cortex markers of suicidal vulnerability in mood disorders: a model-based structural neuroimaging study with a translational perspective. Transl Psychiatry 2015;5:e516.

160. Gosnell SN, Velasquez KM, Molfese DL, Molfese PJ, Madan A, Fowler JC, et al. Prefrontal cortex, temporal cortex, and hippocampus volume are affected in suicidal psychiatric patients. Psychiatry Res Neuroimaging 2016;256:50-56. 
161. Hwang JP, Lee TW, Tsai SJ, Chen TJ, Yang CH, Lirng JF, et al. Corti$\mathrm{cal}$ and subcortical abnormalities in late-onset depression with history of suicide attempts investigated with MRI and voxel-based morphometry. J Geriatr Psychiatry Neurol 2010;23:171-184.

162. Gifuni AJ, Ding Y, Olié E, Lawrence N, Cyprien F, Le Bars E, et al. Subcortical nuclei volumes in suicidal behavior: nucleus accumbens may modulate the lethality of acts. Brain Imaging Behav 2016;10:96-104.

163. Lee YJ, Kim S, Gwak AR, Kim SJ, Kang SG, Na KS, et al. Decreased regional gray matter volume in suicide attempters compared to suicide non-attempters with major depressive disorders. Compr Psychiatry 2016;67:59-65.

164. Colle R, Chupin M, Cury C, Vandendrie C, Gressier F, Hardy P, et al. Depressed suicide attempters have smaller hippocampus than depressed patients without suicide attempts. J Psychiatr Res 2015;61: 13-18.

165. Fan T, Wu X, Yao L, Dong J. Abnormal baseline brain activity in suicidal and non-suicidal patients with major depressive disorder. Neurosci Lett 2013;534:35-40.

166. Cao J, Chen X, Chen J, Ai M, Gan Y, Wang W, et al. Resting-state functional MRI of abnormal baseline brain activity in young depressed patients with and without suicidal behavior. J Affect Disord 2016;205:252-263.

167. Kang S, Na K, Choi J, Kim J, Son Y, Lee YJ. Resting-state functional connectivity of the amygdala in suicide attempters with major depressive disorder. Prog Neuropsychopharmacol Biol Psychiatry 2017; 77:222-227.

168. Jollant F, Lawrence NS, Giampietro V, Brammer MJ, Fullana MA, Drapier D, et al. Orbitofrontal cortex response to angry faces in men with histories of suicide attempts. Am J Psychiatry 2008;165:740-748.

169. Jollant F, Lawrence NS, Olie E, O’Daly O, Malafosse A, Courtet P, et al. Decreased activation of lateral orbitofrontal cortex during risky choices under uncertainity is associated with disadvantageous decisionmaking and suicidal behaviour. Neuroimage 2010;51:1275-1281.

170. Pan L, Segreti A, Almeida J, Jollant F, Lawrence N, Brent D, et al. Preserved hippocampal function during learning in the context of risk in adolescent suicide attempt. Psychiatry Res 2013;211:112-118.

171. Pan LA, Hassel S, Segreti AM, Nau SA, Brent DA, Phillips ML. Differential patterns of activity and functional connectivity in emotion processing neural circuitry to angry and happy faces in adolescents with and without suicide attempt. Psychol Med 2013;43:2129-2142.

172. Miller JM, Hesselgrave N, Ogden RT, Sullivan GM, Oquendo MA,
Mann JJ, et al. Positron emission tomography quantification of serotonin transporter in suicide attempters with major depressive disorder. Biol Psychiatry 2013;74:287-295.

173. Nye JA, Purselle D, Plisson C, Voll RJ, Stehouwer JS, Votaw JR, et al. Decreased brainstem and putamen SERT binding potential in depressed suicide attempters using 11C-zient PET imaging. Depress Anxiety 2013;30:902-907.

174. Ryding E, Ahnlide JA, Lindström M, Rosén I, Träskman-Bendz L. Regional brain serotonin and dopamine transporter binding capacity in suicide attempters relate to impulsiveness and mental energy. Psychiatry Res 2006;148:195-203.

175. De Berardis D, Martinotti G, Di Giannantonio M. Editorial: understanding the complex phenomenon of suicide: from research to clinical practice. Front Psychiatry 2018;9:61.

176. Pompili M. Critical appraisal of major depression with suicidal ideation. Ann Gen Psychiatry 2019;18:7.

177. Maj M. When does depression become a mental disorder? Br J Psychiatry 2011;199:85-86.

178. Maj M. "Clinical judgment" and the DSM-5 diagnosis of major depression. World Psychiatry 2013;12:89-91.

179. American Psychiatric Association (APA). Diagnostic and Statistical Manual of Mental Disorders: DSM-5. Arlington: American Psychiatric Publishing; 2013.

180. De Berardis D, Fornaro M, Valchera A, Cavuto M, Perna G, Di Nicola $\mathrm{M}$, et al. Eradicating suicide at its roots: preclinical bases and clinical evidence of the efficacy of ketamine in the treatment of suicidal behaviors. Int J Mol Sci 2018;19. pii: E2888.

181. De Berardis D, Tomasetti C, Pompili M, Serafini G, Vellante F, Fornaro $\mathrm{M}$, et al. An update on glutamatergic system in suicidal depression and on the role of esketamine. Curr Top Med Chem 2020 [Epub ahead of print].

182. Hawton K, Casañas I Comabella C, Haw C, Saunders K. Risk factors for suicide in individuals with depression: a systematic review. J Affect Disord 2013;147:17-28.

183. Orsolini L, Valchera A, Vecchiotti R, Tomasetti C, Iasevoli F, Fornaro M, et al. Suicide during Perinatal Period: Epidemiology, Risk Factors, and Clinical Correlates. Front Psychiatry 2016;7:138.

184. Fornaro M, Anastasia A, Valchera A, Carano A, Orsolini L, Vellante F, et al. The FDA "Black Box" warning on antidepressant suicide risk in young adults: more harm than benefits? Front Psychiatry 2019;10:294. 